\title{
ROTATION VISCOMETERS AND THEIR APPLICATION TO NON-NEWTONIAN MEASUREMENTS
}

\begin{abstract}
A $\mathrm{T}$ the meeting of the Cambridge Rheology Club hold on November 27, Mr. R. McKennell (Ferranti, Ltd.) discussed rotation viscometers and their application to non-Newtonian measurements. He stated that the application of rotation viscometers to non-Newtonian measurements could give riso to serious errors, the magnitude of which depended both on the design of the viscometer shearing mem. bers and on the degree and type of non-Newtonian behaviour. The nature of those errors in coaxial cylinder viscometers was briefly discussed together with the correction terms derived for the more common types of non-Newtonian flow. Errors were eliminated in the cone-plate viscometer by subjecting the sample fluid to a uniform shear rate. A descrip. tion of the Ferranti-Shirley cone-plate viscometor was given, followed by a demonstration of automatic flow-curve plotting to depict the rheological properties of typical non-Newtonian fluids.

During the subsequent discussion Prof. K. Weissenberg emphasized the great advantages of Mr. McKennell's viscometer for practical purposes when ono has to deal with a series of known materials, where it suffices to investigate only one type of action in one direction of space, and check it by only one characteristic, the 'viscosity'. However, for purposes of research into matorials of unknown properties a more elaborate instrument, the rheogoniometer, was required which provided information about all directions in the three dimensions of space with regard to unidirectional and rociprocating actions, and measured 'elasticity' as well as 'viscosity'. The results so obtained were of fundamental importance for attempts to associate a definite colloidal and molecular structure to the materials.

In his reply, Mr. McKennell illustrated how the presence of viscoelasticity, mentioned by Prof. Weissenberg, manifested itsolf in rotation viscometers. An apparent decrease in viscosity occurred
\end{abstract}

which was not due to structural breakdown but to geometric effects associated with the angular displacement betweon the major axes of stress and strain velocity. In order to obtain the true viscosity, a correction term would be applied which was derived from a measurement of the elastic modulus using either a stress method in a rotation viscometer or a rheogoniometer.

Dr. D. A. Kok (University of Cambridge) asked whethor low-viscosity blood serum would be ejected from the cone-plate gap by centrifugal force. The reply was that the capillary forces in the thin fluid layer $(0.05 \mathrm{~mm}$. mean thickness) acted to prevent this. For example, water might bo examined at cone speeds up to 600 r.p.m. If viscoclasticity were present there was a tension along the streamlines of flow which tended to exert a centripetal effect.

Dr. G. H. J. Neville (British Titan Products) inquired if it was valid to oxtrapolate calibration data obtained with low-viscosity standard fluids to the high-viscosity range. Mr. MeKennell felt that the viscometer constants were valid throughout the entire range, but extrapolation was usually necessary owing to the scarcity of suitable Newtonian fluids of high viscosity.

Dr. P. A. G. Munro (University of Cambridge) thought that it might be useful to fit a glass plate to observe the motion of suspended particles under shear. Mr. McKennell agreed, but felt that, unlike that of the rheogoniometer, the design of the FerrantiShirley viscometer did not permit this.

The next meeting of the Cambridge Rheology Club will be held on February 5 at 7.45 p.m., when $\mathrm{Mr}$. W. J. Thompson (University of Cambridge) will speak on "The Rheology of Clay Soils".

Further information can be obtained from $\mathrm{Mr}$. H. G. Muller, Spillers, Ltd., Technological Research Station, Station Road, Cambridge.

H. G. MULuer

\section{AUDIOGENIC SEIZURES}

\begin{abstract}
$\mathrm{T}$ THE increased interest in, and use which is being made of, sound-induced seizures in several species of experimental animals was made manifest at the international colloquium on "The Psychophysiology, Neuropharmacology and Biochemistry of the Audiogenic Seizure" which was held under the auspices of the Centre National do la Rechercho Scientifique at its laboratories at Giv-sur-Yvette, during November 6-9, 1961. The aim of this colloquium was to bring together scientists who are actively working in this field in order that a comparison of their different approaches to this phenom. enon could be made, so that knowledge of the different methods which are being used throughout the world could be assembled, and so that the contributions of these different disciplines to the study of audiogenic seizures could be discussed and correlated.

M. R. A. Chanco (University of Birmingham) posnted out that adaptive convulsions had been de monstrated in certain strains of mice when they
\end{abstract}

fall. He suggested that seizures in animals should not necessarily be regarded as pathological, and introduced the interesting concept that the audiogenic seizure might be regarded as an adaptive escape reaction. He emphasized that convulsive discharges in the brain are associated with the occurrence of both normal and pathological seizures in animals, and that a wide biological frame of reference is necessary before it is possible to assess the significance of what may appear to be an 'abnormal' phenomenon. Other contributors to the colloquium concerned themselves more particularly with the factors which influenced the production and mochanism of the seizures. Throughout the colloquium, however, there wero numerous reforences to Chance's plea that audiogenic seizures should be considered against a wide biological frame of reference.

C. W. M. Wilson (University of Liverpool) pointed out that the audiogenic seizure could be considered from two aspects. When anti-convulsant drugs were 
being investigated the occurrence of the audiogenic seizure could be used as a pharmacological tool in order to provide a method whereby antagonism between drugs acting on the central nervous system could be measured easily and effectively. The occurrence of the seizure demonstrated the point at which an antagonist to the anti-convulsant drug was exerting its effect. Another way in which tho audiogenic seizure could be investigated was to examino it in relation to behaviour in susceptible animals in the same way as sleep or activity may be examined as facets of normal behaviour. Wilson induced seizures in stable groups of mioe which had been living together for at least a week. In these conditions he found that the severity and incidence of the seizures could be increased when strangers (rogues) were introduced into the groups. The magnitude of the effect produced by the introduction of rogues into stable groups in this way was related to the number of rogues which were introduced. It was found that rogues affected the activity of stable groups also, and here again the change in degree of activity was related to the number of rogues which were introduced. Wilson stressed the importance not only of establisking stable groups before investigating the reactions of animals but also pointed out that measurements of the effective doses of drugs may depend on whether the assays are performed in stable or unstable groups.

A. M. Sackler (Long Island University, New York) described the effect of the audiogenic seizure on the weights of various organs in the rat. His evidence suggested that increased secretion of adrenocorticosteroids was associated with the occurrence of seizures and that reductions in uterine and vesicular weights could occur after audiogenic stimulation daily for three weeks. Like A. Soulairac (Faculté des Sciences, University of Paris), he suggested that there is a close relationship between endocrine changes and experimentally induced seizures. From the point of view of the endocrinologist Sackler suggested that the use of auditory stimuli can provide valuable information about metabolic and endocrine mechanisms.

D. Starbuck-Miller (University of Chicago) described a fascinating series of experiments which demonstrated that the frequency and severity of audiogenic seizures in mice is influenced markedly by very low levels of ionizing radiation. She presented evidence which indicated that the radioactive fall-out during 1957-59 was sufficient to enhance the frequency and severity of the seizures in her strain of mice. In addition to the effect of radiation on the occurrence of audiogenic seizures in the $P 1$ generation of mice, she also presented evidence that genetic changes were produced in the subsequent generations which were exposed chronically to radiation of 5-10 times background level, so that the effect of seizure susceptibility in response to radiation became altered. Her evidence suggested that when the audiogenic seizure is used as a tool for investigating the central nervous system, it can be convincingly demonstrated that the activity of this system can be influenced by levels of $\gamma$-radiation of less than $1 \mathrm{r}$.

Z. Servit (Czeckoslovak Academy of Sciences) discussed the audiogenic seizure in terms of reflex and conditioned physiology. He suggested that the central nervous system of the rat is able to form conditioned reflexes during the latent period of the audiogenic seizure, but his experiments showed that it is very difficult, if not impossible, to elaborate a conditioned audiogenic seizure. $\mathrm{He}$ analysed the topography of the reflex are in the audiogenic seizure. $\mathrm{He}$ described how localized morphological and pharmacological procedures in different parts of the brain could be used to interrupt the arc. He concluded that the localization of the motor signs of an audiogenic seizure in rats is determined by the dominance of one functional system. The acoustic receptor and the cortical motor and acoustic regions of the same side play an important part in this system. The dominance of the system can be influenced by the local application of strychnine or alumina cream to the motor or acoustic areas; dominance can be impaired by local injury or exclusion of certain components in the system, including the inferior colliculus on the side on which the initial motor signs first appear in the animal.

J. Bures (National Centre of Research, Czechoslovak Academy of Sciences) described some further experimental evidence in support of the reflex theory of the production of seizure, and indicated that the bulbopontine reticular formation plays an important part in the mechanism which mediates propagation of the seizure discharge from the auditory pathway.

B. E. Ginsburg (University of Chicago) described the importance of genetic factors in the production of seizures in susceptible animals. These factors range from single gene effects such as can be obtained with the dilution gene to multiple factor situations. He pointed out that these genetic factors can modify seizure susceptibility in mice, rabbits and rats, but that comparable instabilities occur only rarely in other mammalian forms, unless the inherited predisposition to epileptic seizures in man is included in the same class. Strains differ in age of maximum susceptibility; diurnal factors, the effects of change in temperature and of diet also affect differently the susceptibility of different genotypes to seizures. Monosodiun glutamate has the ability to reduce the severity and incidence of seizures in some genotypes but not in others. The naturally occurring slight sex difference in susceptibility is greatly magnified by monosodium glutamate so that its protective effect becomes much greater in males than in females. Ginsburg had developed the breeding characters of his colonies to such an extent that it is possible for him to forecast with great accuracy the seizure susceptibility of his different lines. He emphasized the importance of maintaining pure strains in animals which are being used for examination of the audiogenic seizures.

G. Nellhaus (Neurological Institute, New York) described a strain of rabbits which had been selectively bred for seizure susceptibility. The incidence of seizure susceptibility is almost 100 per cent and seizures characteristically occur during the seventh to eighth weeks of life. The seizure pattern in these rabbits differed from that described in rats and mice, but, like Ginsburg, Nellhaus stated that a highly standardized seizure susceptibility could be produced by selective breeding, and that this could prove an excellent model in the study of epilepsy.

A number of papers dealt with the effects of drugs on the production of audiogenic seizures. G. Quadbeck (University of Saarland) discussed the importance of the blood-brain barrier. He pointed out that trypan blue affected the severity of audiogenic seizures, and later the ability of such drugs as adrenaline, reserpine and metrazol to pass the barrier and 
affect the occurrence of the seizures was discussed. E. A. Swinyard (University of Utah) compared the seizures induced by electro-shock, metrazol and audiogenic stimuli in audiogenic-seizure-susceptible mice of different selected strains. He found that the patterns of maximal seizures induced by these different methods were very similar, but that the seizure susceptibility of the mice varied in responso to tho differont stimuli. The sensitivity of all his strains to motrazol was similar, but he was able to demonstrate significant differences to drugs which depress tho central nervous system when mice in the different strains were subjected to cloctro-shock and audiogenic seizures. These pharmacological observations were supported by the report of M. Niaussat and P. Laget (Centro National de la Rechorche Scientifique, France), who demonstrated differences in the electro-encephalograms of mice with audiogenic and metrazol-induced scizures, A. Lohmann and R.-G. Busnel (Centro National de la Recherche Scientifique, France) reported their investigations on the uso of drugs which altered sorotonin-levels in the brain in scizure-susceptible mico. They found that the concentration of serotonin was identical in both susceptible and resistant sub-lines and that audiogenic seizuros did not change it. Howevor, they found that a decrease in the concentration of serotonin produced by reserpine increasod the intensity of the convulsions, and that an increase in the level produced by monoamine inhibitors, serotonin itself, or its predecessors decreased the intensity of the convulsions.

N. Plotnikoff (Stanford Research Institute, California) showed how drugs could be used to investigate different phases of the audiogenic seizure. He found that tranquillizers could provent the pre-convulsivo phase of wild-running and convulsions, whereas sedatives prevented only the convulsive phase in his strains. If tho mice were given an opportunity to escape from the chambor during the audiogenic stimulus, he found that the escape response could be differentially inhibited by sedativo and tranquillizing drugs. The different strains which he used varied in their responso to difforent pharmacological agonts, and he suggested that differential inbroeding of suscoptible mice could provide a convenient tool for nourochemical investigations of the mochanisms of drugs.

There was ample time for discussion of the points which were raised in all the papers; contributions from those who were working on the different disciplines enabled the participants to discover the advantages of working with physiological phonomena of this nature, and also to appreciato the shortcomings of the methods which they were using. It became clear that several differont species react to an audiogenic stimulus by abnormal bohaviour. This behaviour generally takes the form of a soizure which is characterized by a phase of running, clonic and tonic phasos. The details and order of these phases vary from spocies to species and with different strains in the species. Alterations in the form of the seizures can also be induced by changing the sound stimulus, the animals' environment, diet and various other factors. Drugs may intensify, inhibit or otherwise change the severity and sequence of events in the seizures. It became clear that the audiogenic seizure could provide a ficld of interest for further investigations in many difforent disciplines; tho pooling of the knowledge from these different disciplines stimulated discussion and thought about the physiology of the brain, and the ways in which the audiogenic seizure could be used as a model for discovering moro about human opilepsy.

It was realized during the courso of the colloquium that it would bo necessary to standardize the descriptions and nomenclature of the different phases of the audiogenic seizure. It was agreed that all known strains in all species which are susceptible to audiogenic seizures should be registered, and that workers in this field should attompt to maintain pure lines among their strains and roport any alterations in their characters. In order to co-ordinate work with audiogenic seizure susceptible strains of animals, and to assist any workers who wish to obtain susceptible animals for their investigations, an international committee was appointed with two represontatives from each of the participating countries. The British representatives are M. R. $\Lambda$. Chance (University of Birmingham) and C. W. M. Wilson (University of Liverpool). It was arranged that the proceedings of the colloquium would be published by the Centre National de la Rechercho Scientifique; this publication will contain a complete bibliography of all the papers which have been published on audiogenic seizures. It is proposed that the publication will also contain the recommendations of the committee regarding the nomenclature and description of the $\begin{array}{ll}\text { audiogenic seizure. } & \text { C. W. M. WILson }\end{array}$

\section{PRESENTATION OF SCIENCE THROUGH TELEVISION}

IN a Cantor Lecture delivered to the Royal Socioty 1 of Arts on May 1, 1961, Dr. Tom A. Margerison described how science could bo presented on television not only to the specialist audience but especially to the layman ${ }^{1}$. In spite of the absolute nocessity of science and technology, the 10-15 per cont of the population who guido the destiny of Britain, the professional men, the majority of teachers, the industrialists. the politicians, are almost completely ignorant about science. The bridging of this gap in this most influential part of the population is of great urgency. There aro many ways in which tolevision can holp to closo the gap within the framework of the present programme structure.

The main function of a telovision programmo is to appeal to a largo part of the population. While the 'influential crust' shows little interest in science, the remainder of the population is more interested in scientific subjects than any other type of serious programmo. Scientific programmes appear to be of spocial interest to the growing body of technicians in industry: mechanics, plant controllers, radio and electronics exports, eloctricians, welders and a host of others. They seom to be more interesting to mon than to women. Tho degree of interest is shown by the size of the audience, which, for recent scientific programmes, has boen about five million.

In presenting programmes on scientific subjects, the television services aro doing more to influenco Britain's attitude to scienco than any one other medium. Recently, Sir Lawronce Bragg gave a 